\title{
Engaging and Empowering Student Representatives as Agents of Change at The University of Nottingham Ningbo China
}

\author{
Claudia François, Filippo Gilardi, Dunant Halim, Thomas Hirzel, K Cohen Tan \\ University of Reading, University of Nottingham Ningbo China
}

\begin{abstract}
The Learning Community Forum (LCF) is one of three student feedback mechanisms at The University of Nottingham Ningbo China (UNNC). The other two - Student Evaluation of Module (SEM) and Student Evaluation of Teaching (SET) - are administered by the University, while the LCF is a student-led forum where views regarding the provision of teaching and learning in general are collected and voiced. Whilst the LCF may potentially identify issues that are otherwise overlooked by university-sanctioned surveys, it is confronted with various challenges. This paper investigates the challenges and problems encountered by LCF student representatives by looking at two case studies: the LCFs of the Language Centre (LC) and of the Department of Mechanical, Materials and Manufacturing Engineering (MMME) at UNNC. The study aimed at identifying areas that worked well and those that needed improvement through interviews with student representatives to provide input for the design of a Nottingham Advantage Award (NAA) module. The NAA, as an instrument to address those identified challenges and problems, provides the following: 1) formal recognition of student contribution to teaching and learning; 2) training and relevant skills to empower student representatives as agents of change; 3 ) increased future employability for students through encouraging active reflection on their experience.
\end{abstract}

\section{The Learning Community Forum at The University of Nottingham Ningbo China Function and Relevance}

The Learning Community Forum (LCF) at The University of Nottingham Ningbo China (UNNC) is a student-led forum that takes place at School-level once every semester during term time, with, in attendance, at least an academic Senior Tutor or an LCF staff representative representing the School. Unlike the other two University feedback mechanisms - Student Evaluation of Module (SEM) and Student Evaluation of Teaching (SET) - which take the form of structured questionnaire surveys for every registered module delivered by the School, we encourage students to chair the LCF meetings and minute them. If students do not feel comfortable doing so, an academic member of staff may chair the meeting and, in some schools, the minutes may be taken by an administrative member from the respective Faculty Offices. Topics discussed within the LCF meetings typically involve wider systemic issues that could directly or indirectly influence students' experience and learning process, as opposed to the relatively narrower focus of individual modules.

Those topics may include the provision of facilities, e.g. IT and library services, or they may reflect concerns that are specific to each cohort: for example, final year students might be concerned about internships and career advice whilst Year 2 students might wish for more 
advice on student exchange abroad. Because of this, there is considerable latitude in the scope of discussion within the LCF forum. The role of the Senior Tutor or the LCF staff representative is either to address those points within, where possible, the meeting itself or, where they require further deliberation, to raise them at subsequent School meetings to determine the appropriate response (whether this involves a change in existing practice or policy) before communicating the School's response by reporting back to the student body.

Because of its nature as a student-led forum, rather than a top-down approach to collecting feedback, the success of the LCF in delivering change depends directly upon the quality and relevance of the feedback that is brought to the table by student representatives. And, unlike the generic questionnaire surveys that are uniformly administered throughout the university, the LCF has the potential to raise issues that might otherwise fall between the cracks - this is why the University takes LCF feedback very seriously. At the end of each academic year, a meeting between the Vice Provost for Teaching and Learning, the Campus Senior Tutor and the Faculty Directors of Teaching is held to review the year's LCF minutes across all faculties, identifying key trends and issues in feedback/comments to report back to the Campus Teaching Committee.

\section{Challenges and the NAA as an instrument to address them}

As mentioned above, there is considerable room for uncertainty and ambiguity, since the concerns raised within each School may differ widely; variation in student enrolment numbers within each School further compounds this. Given that there is a total of eighteen LCFs at UNNC, the major challenge here is to ensure that the LCF platform delivers equitable levels of student engagement and consistency in across-the-board feedback that may be actionable.

Three key factors make this difficult to achieve in practice:

Firstly, because the Students' Union (SU), which is in charge of training LCF representatives through its Education Network, is a student society at UNNC and not a professional body (unlike the SU in the UK), there is some limitation to the quality of training and recruitment services that could be provided for and expected by its members;

Secondly, student representatives may become demotivated and subsequently disengaged from the process if or when they do not see the University take immediate action in response to their feedback, as may be the case if issues raised at LCF within a given academic year are addressed and implemented only in the following year - systemic issues raised usually involve a change in existing policies or they require formal approval by Management Board because they involve significant expenditure in funding;

Thirdly, cultural differences between UK HE and our students from a Confucianist background should not be discounted, particularly in terms of what a "collectivis[t] and democratic representation" (NUS, 2012: 4) might mean within the Chinese context. This has a direct, negative impact on "the participation of students in quality enhancement and quality assurance" (QAA, 2015: 4) that could otherwise improve their educational experience. The majority of students participating in the LCFs are Chinese. After joining an LCF as LCF reps, they 
sometimes find themselves confronted by unique challenges (e.g. a general reluctance to voice and identify problems) that are rooted in their cultural and educational background. Compared to Western students, it appears at first sight that Chinese students in general are quieter and less engaged, yet our experience as LCF coordinators showed that these students do want to engage actively in the LCF, though some of them, and especially Year 2 students, feel that they lack the means to do so. For example, some of these students might not only lack confidence to converse in English but might also struggle with writing feedback reports and meeting minutes. Language issues, however, are only part of the problem. In contrast to Western education, that in China places far less emphasis on developing students' independent analytical and critical thinking. When given the task of analysing data and open comments in an LCF survey and then summarising results, Chinese students, often struggling to identify the most relevant data and open-ended comments, ended up by paraphrasing the results in their own words and thus unintentionally preventing them from being actioned.

For these reasons, we needed an instrument or means by which to empower our Students' Union, by enabling it "to contribute to educational and institutional change" (NUS, 2012: 5) and provide students with "an inclusive environment for learning" (QAA, 2015: 4). The Nottingham Advantage Award (NAA) scheme described below offered us the ideal solution for enhancing students' engagement while maintaining the student-led nature of the LCF, as well as aligning it with the UK Quality Assurance Agency indicators (QAA, 2015) by ensuring "that student representatives [...] [had] access to training and ongoing support to equip them to fulfil their roles in educational enhancement and quality assurance" (QAA, 2015: 11). This in turn would serve to create an environment where "students and staff engage[d] in evidence-based discussion based on mutual sharing of information" (QAA, 2015: 12) and give "opportunities for all students to be heard" (QAA, 2015: 10).

To meet these challenges, the NAA scheme appeared to be the ideal solution because of its constructivist nature. According to Otting and Zwaal, "Constructivist views of learning emphasize learning processes in which students actively construct knowledge for themselves in interaction with rich and authentic learning environments. Therefore, pedagogical practices like project work, workplace learning, and action learning, which stress active and collaborative learning activities, might also fit in a constructivist framework." (2007: 172).

The NAA scheme is a cross-campus award (UK, China and Malaysia) that provides accreditation to students learning outside the formal curriculum. Students involved in this scheme gain transferable skills through participation in extra- and co-curricular activities that enhance leadership skills and boost the employability of students by providing them with skills that are not necessarily part of their usual academic learning outcomes (Speight, Lackovic and Cooker, 2012).

In addition to the QAA-related improvements described above, the added advantage of using this instrument to empower our students meant that LCF student representatives would see their contribution formally recognised and their employability improved.

The aim of the NAA is to help students - particularly Chinese students - to develop effective 
communication and report-writing skills in English by creating an environment in which they feel supported and encouraged. The NAA as a framework further supports students to develop the ability to engage critically with data analysis and open-ended comments in the LCF survey. In this way, the NAA module is committed to help students to exploit their potential in the best possible way.

\section{Research Design}

To ensure fitness of purpose as well as relevant student input towards the design of the LCF NAA module that would run in academic year 2015-16, we conducted two case studies within the Language Centre (LC) and the Department of Mechanical, Materials and Manufacturing Engineering (MMME) in the autumn semester of 2014-15, with the aim of identifying the areas within the LCF that were working well and those that needed improvement.

These two units were chosen for the following reasons: the LC teaches five languages (French, German, Spanish, Mandarin and Japanese) to students from such departments as International Communications (IC), English Studies (ES), International Business (IB), International Economics and Trade (IET) and International Studies (IS). In other words, the student mix taught by the LC made up two out of three faculties here at UNNC and was therefore an efficient way to ensure diversity in terms of disciplines and backgrounds. Meanwhile, the Department of MMME (belonging to the third remaining faculty) followed a strict procedure that was clear and explicitly designed with data-collection in mind and was for this reason an ideal choice as a control group. The two units taken collectively represented an exhaustive crosssection of the student enrolment at all three faculties.

For the interviews in both case studies, a questionnaire was set up. The questionnaire for the interviews was designed by the research group and consisted of three parts:

1. The questions in the first part inquired into the motivation and expectations of students before signing up for the LCF;

2. Questions in the second part touched upon issues encountered during the LCF process, such as leadership and team work within the LCF, the support structure and opportunities to develop personal and professional skills, commensurability of workload, the relevance of the LCF and the quality of feedback;

3. Questions in the final part addressed further issues, looking at how LCF reps benefited from their experience with respect to their future career, how the LCF could be made completely student-driven and how junior undergraduates could be encouraged to sign up for the LCF.

This questionnaire was approved via the ethics review process at UNNC. The two case studies are presented separately below with their findings, together with the organisation of existing LCF practices within each unit, problems identified within them and feedback collected through interviews from student representatives. A summary of common issues encountered will be discussed and, following this, the design process of the NAA module will be described to address the issues that emerge from the two case studies. 


\section{Case study 1: Language Centre LCF}

At the beginning of the autumn semester, the SU recruited student representatives for the Language Centre LCF on a voluntary basis, from different schools and studying one of the languages delivered by the LC. The LCF consisted of thirteen student representatives from Year 2 to Year 4, drawn from five different Schools (IC, ES, IB, IS and IET), and a staff representative from the LC. As the LC is part of the School of International Communications (IC), it is mandatory for IC students to study a language component with the LC.

Previous LCF discussions at the LC were unsatisfactory, as many of the issues raised had already been covered by existing SEM and SET surveys. Apart from the replication of feedback, many of the issues were not specific enough and, at times, irrelevant to the majority of students. Because of this, the remit of the LC-LCF was to develop a new questionnaire that was meaningful and relevant to the Language Learning Process of these students (e.g. self-study, in-class activities, language labs, extra-curricular activities, workshops on specific skills) so that they might be addressed by language tutors as well as by the Director of the Language Centre. It also provided the Director of the Language Centre with the necessary figures and constructive comments to initiate such changes as rethinking the assessment method.

The better to organise the LCF, the following roles were assigned by the staff coordinator, based on students' interest and abilities:

I. Questionnaire representative: This student was responsible for setting up the questionnaire on the Qualtrics software and making the survey accessible on Moodle for all students studying at the LC. After the survey was completed, this student gathered the data from Qualtrics and handed it over to the feedback collection representatives;

II. Feedback collection representatives: After receiving the survey results from the questionnaire representative, the feedback collection representatives divided the data into nine categories, including survey results for IC students studying French, German, Japanese, Mandarin or Spanish (divided by language specialisation), as well as for ES, IB, IET and IS students studying a language at the LC (divided by external schools). The results of these nine different groups of students were then sent to the representatives for these groups;

III. Five IC representatives for French, German, Japanese, Mandarin and Spanish: Each of these IC language representatives was responsible for covering one of the five languages taught at the LC. These representatives summarised the survey results and comments and afterwards sent the summary back to the feedback collection reps;

IV. Four representatives for ES, IB, IET and IS: Though these representatives had the same responsibilities as the five IC representatives above, they represented the students from the four schools above, regardless of the language modules they took at the LC. For example, this meant that the ES student representative would cover feedback from all ES students, even if they were studying different languages; 
V. One Meeting Minutes representative: This representative was responsible for taking the minutes of the LC-LCF meeting at the end of the semester. For this purpose, the representative did a voice recording of the LCF meeting, wrote down the minutes and sent them to the LCF staff coordinator.

The questionnaire design was a team effort, to avoid any potential blind spots, as the LC-LCF team wanted to avoid replicating feedback covered by SEM and SET surveys as well as to limit the number of questions, in order to make the whole process more manageable.

The LC-LCF team brainstormed relevant broad-based questions and divided them into seven categories consisting of thirty-eight questions in total. These included attendance policy, examinations, learning environment, availability of staff to students, communication and information, students abroad and on exchange, and other general questions. Students were given the option to indicate their response, using a six-point Likert scale ('strongly agree', 'agree', 'neutral', 'disagree', 'strongly disagree' and 'non-applicable') and they were also given space to provide further comments on each of the seven categories. In addition, the questionnaire also asked students to provide suggestions regarding other questions that might have been overlooked. The questionnaire was subsequently uploaded on Qualtrics by the questionnaire representative and made accessible on Moodle to all LC students; LC tutors were asked to give students fifteen minutes during class to complete the survey.

After the survey was completed, the results were divided among the nine language representatives, each comprising between thirty-four and forty-five pages of raw data, including figures, graphs and text. These were subsequently summarised in three to four pages. To ensure consistency across the different summaries drafted by each representative, students were asked to work in groups for proofreading and data-checking, using standardised pro forma. The summary for each group was forwarded to the LCF staff coordinator for final checking. If more information or clarification were needed, the coordinator would send it back to the relevant student representatives and the final version would be then circulated amongst LC tutors, seeking their response.

During the LC-LCF meeting at the end of the semester, the issues raised by students and the response of the tutors were summarised by the Director of the Language Centre and discussed by students and tutors attending the meeting. At the end of this process, the Language Centre Senior Tutor approved the meeting minutes and response from the School and these were uploaded to Moodle and Workspace.

\section{Case Study 1: Findings and Interview}

Although this was the first time the LCF had conducted an online survey, there were no substantial problems encountered in the process. The LCF received a total of 733 responses to the online survey, representing approximately $80 \%$ participation rate by the students. This fell short of the $100 \%$ participation rate that the team had hoped for. Some of the initial summaries of the received data needed revision up to three times, as they contained various inaccuracies or were structurally unclear. The same was true of the meeting minutes. As these would be 
published to the student body, it was crucial that both the feedback and the minutes were presented in a clear and professional manner.

Three student representatives were later interviewed on a one-to-one basis, to find out about their perception of the LCF in terms of its usefulness for the improvement of teaching and learning, as well as about the extent of its contribution to their own personal development. The students interviewed demonstrated an awareness of the importance of the LCF and saw their own involvement as agents of change, something shared by their tutors, in terms of how they planned or delivered teaching. The students also saw the LCF approach as being "democratic", offering an opportunity for "students [to] decide for students". In this regard, they felt empowered in the role they played as student representatives. Students also observed improvements in their personal and professional skills (such as team work, interpersonal communication, written communication and time-management) and believed that participation in the LCF could be advantageous to their future employability. This is culturally significant in China, where there is an emphasis on extra-curricular activities and "good works" benefiting the community, in addition to academic achievement (Hustinx et al, 2010).

However, the student representatives also highlighted a number of issues that made their task more difficult, which were taken into consideration when designing the NAA module for the LCF. The top priority for student representatives was to ensure that the NAA structure was clear and did not impose further demands on their time, because, in addition to gathering student feedback and speaking to course peers, they were concerned that they would have to fulfil the module credits in order to receive the accreditation. Indeed, some student representatives were forced to quit halfway through the academic year because they needed to focus on their studies. If the NAA module were too time-consuming, it would make future recruitment more difficult.

The student representatives also indicated that they would like both a clearer definition of roles and expectations, to ensure that everyone in the group knew what s/he was doing, and a progress chart with clearly-defined deadlines, to minimise confusion. They also expressed some frustration with the multiple revisions of their report and hoped that the NAA module would include training in relevant skills such as report-writing, minute-taking and agenda-drafting. This would allow student representatives to carry out their tasks with greater confidence and professionalism. They also expressed a desire for team-building activities to foster better communication between team members, which might then have prevented some team members' dropping out halfway through the year and some classes' not being informed of the LCF questionnaire owing to a lapse in communication.

\section{Case Study 2: Department of Mechanical, Materials and Manufacturing Engineering LCF}

During their first week of the academic semester, students were given a short fifteen-minute presentation about the LCF and its importance during class. This presentation was given by the staff LCF representatives and was intended to raise student awareness about the LCF and its process. After the presentation, the lecturer and LCF staff representatives left the room for about ten minutes to provide students with an opportunity to have free discussion with their 
peers, following which they were asked to elect two student representatives. Two student representatives were elected for each year of study from two courses, namely mechanical engineering and product design and manufacture. Additional support was provided by the Students' Union Education Network, by means of organised training for the student representatives, and all the representatives' details were uploaded to the notice board outside the Faculty Office, to Moodle and to Workspace, so that students would be able to identify their LCF representatives.

During the semester, the departmental LCF staff representative requested feedback from student representatives a few weeks in advance of their LCF meeting and student representatives then collected feedback from their fellow students using any method they wished - e.g. face-to-face meeting, paper questionnaire, WeChat, and emails. They could also request time in class to do this with the lecturer absent. The student feedback was then sent to the departmental LCF administrator (a member of the Faculty Office) who combined the feedback from all the student representatives into one document and passed it on to the staff LCF representatives. The departmental LCF staff representatives addressed the feedback, approached colleagues where necessary and then met with the student representatives. The chair was normally the LCF staff representative and the departmental senior tutor was invited to the meeting. The LCF minutes were then drafted by Faculty Office staff, checked and finally agreed upon by all members of the LCF; they were finally disseminated in the department and uploaded to Moodle/Workspace for the information of students and staff.

\section{Case Study 2: Findings and Interviews}

Four LCF student representatives from the Department of MMME volunteered to be interviewed following the completion of the LCF meetings at the end of the year. Among the motivating factors identified were: the opportunity to help fellow students; the ability to improve the student learning experience; the opportunity to interact with academic staff and other students in this LCF environment. It was observed that their motivation was not primarily influenced by the need to include their LCF experience in their student CV for postgraduate study or future employment, as these student representatives did not see the skills and experiences they obtained through participation in the LCF to be relevant and formalised enough to be included. Nonetheless, the student representatives interviewed felt that transferable skills gained in the process, such as communication, leadership and data collection, were important and wanted to develop them in a more formal and structured setting.

The four student representatives reported that their responsibilities did not take up too much of their time and felt that their workload was manageable, because, they affirmed, they had received adequate support from other student representatives on their team as well as from the LCF academic staff. This kept them motivated to continue their LCF responsibilities throughout the year.

However, there were some issues that were felt to be less than satisfactory to the student representatives interviewed. Chief among these was their perception that they were unable to create as much change as they had hoped. They felt that certain issues raised during the LCF 
meetings had not been adequately addressed by either the department or the University, and wanted the LCF platform to be given greater power to implement changes. This was, for some of the student representatives, a potentially de-motivating factor re continuing in their LCF roles. Whilst the university is committed to placing students at the centre of the learning and teaching process, there are various constraints, in terms of infrastructural change and government policy, that cannot be decided by the University without further consultation. The staff coordinator felt that greater knowledge and understanding of the University and how it operates would have helped to defuse some of the frustration felt by the student representatives.

\section{Common Issues}

From the data collected during both case studies, we were able to identify some common issues arising from the existing LCF practice that should be addressed in the design of the LCF NAA module. These include:

1. Incommensurability of workload: This was most apparent in the feedback from both sets of interviews, as student representatives from the LC felt that participation in the LCF was time-consuming compared to the student representatives from the Department of MMME. This was certainly owing to the number of students taking language modules within the LC, as well as to the fact that the LCF members in the LC comprised students from different departments and faculties. The mix of academic backgrounds presented an impediment to effective communication and organisation because of timetabling differences. In addition, membership of the LC LCF dropped from fifteen to eight members after Christmas, and this had a workload impact on the rest of the team. This was not an issue in the second case study, as the student representatives were from the same department. However, this also highlighted a need for structure and clarity within the LCF framework;

2. Quality assurance in terms of training and feedback: Relevant skills and training should be provided in a formal setting to support student representatives to support student representatives and boost their confidence. This would help them carry out their responsibilities with an equal level of support. The transferable skills learnt could then also be listed in the student CV for either postgraduate study or future employability;

3. Understanding how the University operates: This would help to manage the expectations of student representatives and to foster their greater professionalism, by increasing their exposure to University, academic faculty and department structures. The knowledge and understanding gained would allow them to identify more effectively areas of improvement to be implemented. It would also boost their level of engagement and enable them to work alongside academic staff to deliver change. Research on this subject indicates a positive correlation between the level of student engagement and the quality of their learning: students who engage in such extra-curricular activities are also the most engaged in their studies, and the assumption here is that the converse is true. Students who get involved in extra-curricular activities will eventually show more interest in their studies as a result (Graham Gibbs, 2016), especially if these activities bring a 
sense of satisfaction, fulfilment and belonging to the students in question. This will eventually have impact on the institution's image (Trowler, 2010);

4. Formal recognition of student contribution to teaching and learning: The accreditation offered by the NAA award is consistent with the University's commitment to placing students at the centre of our teaching and learning. It would also improve the future employability of student representatives and reward them for their time. More importantly, this would be a strong motivating factor in the recruitment and retention of LCF representatives, particularly for Chinese students, who highly value extrinsic motivation ( $\mathrm{Li}, 2003$ ). All student representatives interviewed, in fact, felt that the proposed LCF NAA module was attractive to them. One student representative expressed an interest in continuing to serve in this role only if it were possible for her to take it as part of the NAA. The retention of LCF student representatives is important as it would allow more experienced student representatives to take on mentoring and training roles within the LCF and the SU Education Network in future, thereby increasing its autonomy over time.

\section{LCF Nottingham Advantage Award (NAA) Module Design}

Following the findings from the two case studies, an LCF-NAA working group was formed and tasked with designing the NAA module for its pilot in autumn semester of 2015-16. The working group was composed of key stakeholders identified on the basis of the support they could provide, as well as on the direct and indirect effects on their work as a result of the NAA scheme. The different stakeholders were then assessed on the basis of their attitude vis-à-vis the project, their interest in it and the support they would be able to provide if we were able to engage them (Jisc, 2015). These stakeholders were:

- $\quad$ Senior Tutor Network (STN): A cross-faculty network of Senior Tutors from different schools. As students would take the module from different schools it was felt that a campus-wide network would maintain focus and relevance to the content and objectives of the NAA module;

- LCF staff representatives: The LCF staff representatives' involvement was essential, as they were responsible for providing guidance to LCF student representatives and served as their first point of contact. Their participation was crucial in designing the NAA as well as guaranteeing workload equity across schools;

- Student Representatives from the Students' Union Education Network: It was felt by colleagues that, as it was a student-led forum, it would be beneficial for students to participate in the module design and approval so that it might more closely reflect their needs and demands. This was a significant move, as student representatives from the SU Education Network would eventually lead the workshops to provide the necessary training for LCF student representatives, after being trained on the delivery of these sessions by a staff member. In this way, students would be involved at every stage of the NAA design process, from the inception stage (via feedback from interviews), to the design and planning stage (via working group) and finally to the delivery and execution 
stage (via leading workshops and recruiting LCF representatives in elections). This was in line with the Developmental Model of Student Engagement (DMSE) that "locates students as partners in a learning community, and [...] places greater emphasis on student growth and development and is primarily concerned with the quality of learning and the personal, mutual and social benefits that can be derived from engaging within a community of scholars" (Trowler and Trowler, 2010: 3);

- Teaching and Learning Enhancement Office (TLEO): In charge of advising the academic community regarding best practice and all quality assurance related work at UNNC; supportive of the SU Education Network members and all activities, procedures and policies related to Teaching and Learning;

- Career Development Office: In charge of the administration of the NAA programme;

- Campus Teaching Committee (CTC): In charge of the University's academic quality standard. It reviews and develops the University's teaching and learning strategy.

The NAA module had three objectives and four components of assessment and could be taken either as a 10-credit module (100 hours in total for students on one semester exchange in Year 3 ) or a 20 -credit module (200 hours in total). The three objectives of the NAA module were:

1) to ensure that students' concerns about their courses of study were represented to academic staff throughout the academic year;

2) to ensure that the views of students were given proper weight in the processes of course and module review;

3) to provide an opportunity for students to develop a broad range of transferable skills and to work in partnership with other students and academic staff.

In order to meet the above objectives, the method of assessment contained four components, in at least three of which students must attain a compulsory pass mark. The four components of the NAA module were as follows:

i. Knowledge: Three sets of ten multiple choice questions deployed as online quizzes on Moodle. These questions covered knowledge of the University, including the University's Quality Manual and the services provided to students. A $100 \%$ pass mark was required on each set of questions before student representatives were allowed to proceed to the next stage, although they were allowed to re-take the quiz as many times as necessary;

ii. Application: Writing of meeting minutes. Pass marks were awarded by the Campus Senior Tutor during the LCF annual review or by the School's LCF staff coordinator, based on the quality and value of the issues discussed at the LCF meeting;

iii. Team-work: A peer evaluation of each individual student representative would be conducted by the team to ensure commensurable levels of participation and effort. This would also reinforce team-building and engagement within each team;

iv. Reflection: Each team would produce a ten-minute self-reflective video, based on their experience as LCF representatives and what they had learnt in the process. This would be awarded a pass/fail mark by representatives from the SU Education Network, which was initially responsible for leading the workshops. 
It should be noted from components iii and iv that students had equal weight and say in terms of the assessment for the NAA module. This decision was informed by the findings of the interviews as well as the LCF-NAA working group, in order to devolve greater responsibility and autonomy to the LCF representatives. According to Healey, Flint and Harrington, "engaging students as teachers and assessors in the learning process is a particularly effective form of partnership" (2014: 8). This would also be a motivating factor for student representatives and the purpose of the LCF-NAA was to support rather than direct the LCF platform; the LCF would otherwise lose its unique characteristic as a student-led platform and become re-appropriated as yet another formal means of feedback. The components were to be awarded pass/fail marks rather than graded because they were intended to be formative/evaluative. The module was also extended to include postgraduate students so that it might help in their personal and professional development; it was piloted successfully in autumn 2015-16.

Based on the Four Modes of Student Engagement model proposed by Dunne (2016), the LCF student representatives participated in student-led activities that were focused on both critical thinking (mode A) and design thinking (mode B). In mode A, student representatives proactively engaged with their peers to collect feedback, using a variety of data collection methods, and to perform an evaluation based on the critical analysis of the feedback data. In mode B, student representatives utilised the evaluation results to initiate ideas and action to promote changes in their department via the LCF process. The LCF-NAA module, however, incorporated a more formalised teacher-led aspect to the whole process in order to improve student engagement in this mainly student-led activity. Various aspects were contributed by teacher-led critical-thinking (mode C) and design-thinking (mode D) activities, in which teachers guided the students through more formative assessment for developing their skills in writing meeting minutes and data collection methods, as well as for encouraging them to engage with their peers via a peer evaluation and team self-reflective videos. In other words, when the students undertook the LCF-NAA module, there was a gradual shift in focus and responsibility from teacher-led modes ( $C$ and $D$ ) to student-led modes ( $A$ and $B$ ). The aim was to leverage student engagement, first by guiding them through critical- and design-thinking elements and finally empowering them to take on effective leadership roles as agents of change through the LCF process.

Colleagues within the working group intended to gather more information and feedback on the LCF-NAA pilot at the end of the year for further development of the module.

\section{Reference list}

Dunne, E. (2016) 'Design Thinking: A framework for student engagement? A personal view.' Journal of Educational Innovation Partnership and Change, 2(1). Available at: http://dx.doi.org/10.21100/jeipc.v2i1.317 (Accessed: 30 August 2016).

Gibbs, G. (2016) ' 'Student engagement' is a slippery concept. 53 Powerful Ideas All Teachers Should Know About.' SEDA. Available at:

http://www.seda.ac.uk/resources/files/publications 199 42\%20'Student\%20engagement'\%20is \%20a\%20slippery\%20consept.pdf (Accessed: 30 August 2016). 
Healey, M., Flint, A. and Harrington, K. (2014) Engagement through partnership: students as partners in learning and teaching in higher education. York: HEA. Available at:

https://wwew.heacademy.ac.uk/sites/default/files/resources/engagement through partnership.p df (Accessed: 30 August 2016).

Hustinx, L., Handy, F., Cnaan, R. A., Brudney, J. L., Pessi, A. B., and Yamauchi, N. (2010) 'Social and cultural origins of motivations to volunteer a comparison of university students in six countries.' International Sociology, 25(3), 349-382. Available at:

https://biblio.ugent.be/publication/1114161 (Accessed: 30 August 2016).

Jisc (2015) Stakeholder engagement. Available at: https://www.jisc.ac.uk/guides/changemanagement/stakeholder-engagement (Accessed 30 August 2016).

Li, J. (2003) 'U.S. and Chinese Cultural Beliefs about Learning.' Journal of Education Psychology, 95(2), 258-267.

NUS (2012) A Manifesto for partnership. Available at:

http://www.nusconnect.org.uk/resources/a-manifesto-for-partnership (Accessed: 30 August 2016).

Otting, H. and Zwaal, W. (2007) 'The identification of constructivist pedagogy in different learning environments.' In: McCuddy, M. K. (Ed.) The challenges of educating people to lead in a challenging world. Netherlands: Springer, 171-196. Available at:

http://link.springer.com/chapter/10.1007\%2F978-1-4020-5612-3 9\#page-2 (Accessed: 30 August 2016).

QAA (2015) UK Quality Code for Higher Education. Part B: Assuring and Enhancing Academic Quality. Available at: http://www.qaa.ac.uk/assuring-standards-and-quality/the-qualitycode/quality-code-part-b (Accessed: 30 August 2016).

Speight, S., Lackovic, N., and Cooker, L. (2012) 'Stakeholder attitudes towards employability in a Sino-British university.' Journal of Teaching and Learning for Graduate Employability, 3(1), 2640. Available at: http://itlge.curtin.edu.au/index.php/itlge/article/viewFile/109/28 (Accessed: 30 August 2016).

Trowler, V. (2010) Student engagement literature review. York: HEA. Available at: https://www.heacademy.ac.uk/sites/default/files/studentengagementliteraturereview 1.pdf (Accessed: 30 August 2016).

Trowler, V. and Trowler, P. (2010) Framework for action: enhancing student engagement at the institutional level. York: HEA. Available at:

www.heacademy.ac.uk/resources/detail/studentengagement/Frameworks for action index (Accessed: 30 August 2016). 